\title{
1 Synthesis, Characterization and Biocompatibility of Mesolamellar Calcium Phosphate Hybrids Prepared by Anionic Surfactant Templating
}

\author{
Antonio J. Salinas, ${ }^{[a, b]}$ José M. Blanco-Bécares, ${ }^{[a]}$ Okan Mersinlioglu, ${ }^{[a]}$ Laura Casarrubios, ${ }^{[c]}$ Daniel \\ Fernández-Villa, ${ }^{[c]}$ María J. Feito, ${ }^{[c]}$ Teresa Portolés, ${ }^{[c]}$ Blanca González, ${ }^{\star[a, b]}$ María Vallet-Regíla,b]
}

\begin{abstract}
Calcium phosphate $(\mathrm{CaP})$ based hybrid materials have been synthesized through a precipitation method in aqueous medium in the presence of the anionic surfactant sodium dodecylbenzene sulfonate (SDBS) as structure directing agent. Parameters of synthesis, such as $\mathrm{Ca} / \mathrm{P}$ molar ratio, surfactant concentration and initial $\mathrm{pH}$, have been investigated trying to get mesostructured $\mathrm{CaP}$ phases. A lamellar-like hybrid mesophase consisting in several wavy layers of apatite or apatite-brushite nanoplates was successfully obtained. Materials have been characterized by several physico-chemical techniques. A potential application of these lamellar calcium phosphate based hybrids can be as matrixes in drug delivery systems with the possibility of loading hydrophobic drugs in the organic interlayers. To evaluate their potential as biomaterials, the biocompatibility of two hybrids has been studied in vitro with human Saos-2 osteoblasts. Cell assays showed that, upon the appropriate synthesis and stabilization conditions, a biocompatible CaP and SDBS mesolamellar hybrid can be prepared.
\end{abstract}

\section{Introduction}

Calcium phosphate (CaP) materials are of great relevance as biomaterials due to their unique biocompatibility and bioactivity, which have led to their wide use in bone tissue engineering and therapeutic delivery. ${ }^{[1-6]}$ With this purpose, mesostructured materials, such as ordered mesoporous silica materials both in bulk and nanoparticles, are reaching a great relevance on such

[a] Dr. A. J. Salinas, J. M. Blanco-Bécares, Dr. O. Mersinlioglu, Dr. B. González, Prof. M. Vallet-Regí

Departamento de Química en Ciencias Farmacéuticas (Química Inorgánica y Bioinorgánica), Facultad de Farmacia, Universidad Complutense de Madrid

Plaza de Ramón y Cajal s/n, 28040 Madrid, Spain.

E-mail: blancaortiz@ucm.es

[b] Dr. A. J. Salinas, Dr. B. González, Prof. M. Vallet-Regí Networking Research Center on Bioengineering, Biomaterials and Nanomedicine (CIBER-BBN), Spain.

Instituto de Investigación Sanitaria Hospital 12 de Octubre i+12, Madrid, Spain.

[c] L. Casarrubios, D. Fernández-Villa, Dr. M. J. Feito, Prof. M. T. Portolés

Departamento de Bioquímica y Biología Molecular, Facultad de Ciencias Químicas, Universidad Complutense de Madrid, Instituto de Investigación Sanitaria del Hospital Clínico San Carlos (IdISSC) Ciudad Universitaria, 28040 Madrid, Spain.

Supporting information for this article is available for download via a link at the end of this manuscript. biomedical applications because they present the ability to adsorb biologically active molecules and release them in a controlled manner. ${ }^{[7-11]}$ These ceramic silica-based materials are obtained through a self-assembly process in which supramolecular assemblies of surfactants direct the formation of a mesostructure during the condensation of the soluble inorganic species. ${ }^{[12-14]}$ This technique of surfactant-templating has been used as well to prepare other mesoporous inorganic solids such as metal oxides and alumninophosphates. ${ }^{[15]}$ However, the synthesis of mesostructured CaPs following this approach has been less successful. It is attributed to the fact that the inorganic framework is strongly connected through ionic bonds between calcium and phosphate ions and the CaP crystalline phase is rapidly formed during a precipitation process. The fast generation of discrete crystalline CaPs could hinders the previous interaction of the ions in solution with the surfactants used as templates of the mesophase.

However, biological systems are able to produce organicinorganic hybrid structures through biomineralization processes. ${ }^{[16-18]}$ Then, using biomimetic mineralization methods to fabricate functional materials with ordered nanostructures, many key authors in the field have developed organic-inorganic mesostructures with complex architectures based on $\mathrm{CaPs}^{[19-24]}$ as well as based on $\mathrm{CaCO}_{3}$. ${ }^{[25-26]}$

To date, no clear evidences of mesoporous hydroxyapatite (HA) have been reported. Only very poorly defined hexagonal mesoporous structures using cetyltrimethylammonium bromide as template ${ }^{[27]}$ or possible hexagonal $2 \mathrm{D}$ mesostructures of hybrid materials, whose mesostructure disappears after calcination, using mixtures of anionic and cationic surfactants have been published. ${ }^{[28]}$ Also, the use of non ionic block copolymers has been tried as a neutral templating of mesoporous hydroxyapatite. ${ }^{[29,30]}$ Thus far, mesoporous hydroxyapatite has been produced with a significantly enhanced specific surface area using double emulsion droplets as microreactors. ${ }^{[31]}$ Moreover, a modified hard templating route based in ordered mesoporous carbon as hard template has been used for the synthesis of hydroxyapatite possessing wormlike mesoporosity. ${ }^{[32]}$ Wormhole-like mesostructured hybrid materials using anionic and cationic surfactants gave a mesoporous CaP with a surface area up to $140 \mathrm{~m}^{2} / \mathrm{g}$ at the largest. ${ }^{[33]}$ More recently, an energy efficient microwave approach has been reported for the synthesis of mesoporous $\mathrm{CaP}$ nanorods without the need of organic templates. ${ }^{[34]}$

Therefore, new approaches for the preparation of mesostructured CaPs need to be explored from the first synthetic strategy to produce mesolamellar hydroxyapatite. ${ }^{[35]}$ 
Although it is difficult to suppress the crystallization of CaP species for obtaining mesostructured precursors, the possibility to form lamellar mesostructured CaPs and mesolamellar films growth on titania-titanium substrate were reported by Ozin and coworkers. ${ }^{[35,36]}$ This surfactant-template cooperative assembly using dodecyl phosphate monoesters approach has been published by other research groups. ${ }^{[37,38]}$

Furthermore, the formation of the hybrid CaPs with lamellar mesostructure has been accurately proved by TEM only in a few cases. For example, hybrid mesocrystals with lamellar organicinorganic superstructures at the nanoscale have been prepared via biomimetic mineralization and a co-assembly process in the presence of bovine serum albumin and an anionic sulfonate ( $R$ $\mathrm{SO}_{3}{ }^{-}$) surfactant. ${ }^{[39,40]}$ Mixed solvent systems of alcohol and water have been used to supress the fast and discrete crystallization of crystalline CaP allowing the interaction between surfactant molecules and calcium and phosphate ions. ${ }^{[41]}$ Anionic surfactants with carboxylic acid groups were also able to template mesolamellar phases using this approach. ${ }^{[42] ~ E v e n ~}$ attempts to adjust interlamellar spacing by using linear aliphatic carboxylic acids such as fatty acids have been reported. ${ }^{[43]}$

In this line, a highly ordered mesostructured lamellar hydroxyapatite has been synthetized by the templating approach and using sodium dodecylsulfate (SDS) as anionic surfactant. The proposed mechanism for the lamellar HA is very similar; the surfactant molecules would organize in water media forming bilayer surfactant mesophases via self-assembly. The aqueous layers in between surfactant bilayers would act as nanoreactors where calcium ions strongly interacts with the sulfate $\left(\mathrm{R}-\mathrm{OSO}_{3}{ }^{-}\right)$ groups of the polar heads of surfactant, producing an enrichment of ions in this areas to reach supersaturated values for HA precipitation. ${ }^{[44]}$ Indeed, an interesting potential application as as gene delivery vector has been proposed for this kind of mesolamellar hybrid calcium phophates. ${ }^{[45,46]}$

Therefore, in the case of CaPs it is considered that direct interaction of calcium cations with anionic surfactant molecules is possible during the formation of ionic inorganic frameworks. The lamellar bilayer surfactant mesophases would serve as soft template in the preparation of lamellar CaP hybrid materials. However, as it is expected, there is no possibility of removing the surfactant and maintaining the lamellar mesostructure because thermal decomposition of the interlayers would produce the collapse of the lamellar mesostructure. Regarding possible applications, the inclusion of bioactive guest molecules into the hydrophobic organic interlayer of this kind of hybrid mesolamellar CaP materials, acting as host for drugs, would be a way to expand their potential utility. However, the use of surfactants may compromise this application as biomaterials due to toxicity induced by the surfactant.

In this article we describe the synthesis of a hybrid material based on $\mathrm{CaP}$ with a lamellar mesostructure. The synthetic strategy for preparation is based on the precipitation method in aqueous media in the presence of an anionic surfactant able to interact with the mineral component as well as form lamellar assemblies. Sodium dodecyl benzene sulphonate (SDBS) has been selected as structure directing agent.
Table 1. Materials investigated in this work and sample codes as a function of the synthesis conditions.

\begin{tabular}{|c|c|c|c|c|}
\hline $\begin{array}{l}\mathrm{Ca} / \mathrm{P} \text { molar } \\
\text { ratio }\end{array}$ & $\begin{array}{l}\text { [SDBS] } \\
(\mathrm{mM})\end{array}$ & $\begin{array}{l}\text { Initial pH } \\
\text { control }\end{array}$ & Sample Code & $\begin{array}{l}\text { Sample } \\
\text { weight (g) }{ }^{[a]}\end{array}$ \\
\hline 1.0 & 15 & --- & $\mathrm{CP}_{1}-\mathrm{S}_{15}$ & 0.47 \\
\hline 1.0 & 30 & --- & $\mathrm{CP}_{1}-\mathrm{S}_{30}$ & 0.77 \\
\hline 1.0 & 45 & & $\mathrm{CP}_{1}-\mathrm{S}_{45}$ & 0.90 \\
\hline 1.0 & 60 & --- & $\mathrm{CP}_{1}-\mathrm{S}_{60}$ & 0.86 \\
\hline 1.0 & 90 & --- & $\mathrm{CP}_{1}-\mathrm{S}_{90}$ & 0.94 \\
\hline 1.67 & 15 & 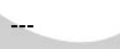 & $\mathrm{CP}_{1.67}-\mathrm{S}_{15}$ & 0.60 \\
\hline 1.67 & 30 & -- & $\mathrm{CP}_{1.67}-\mathrm{S}_{30}$ & 0.76 \\
\hline 1.67 & 45 & -- & $\mathrm{CP}_{1.67-\mathrm{S}_{45}}$ & 0.95 \\
\hline 1.67 & 60 & --- & $\mathrm{CP}_{1.67-\mathrm{S}_{60}}$ & 1.16 \\
\hline 1.0 & 30 & 9 & $\mathrm{CP}_{1}-\mathrm{S}_{30}(9)$ & 1.23 \\
\hline 1.67 & 15 & 9 & $\mathrm{CP}_{1.67-\mathrm{S}_{15}(9)}$ & 1.15 \\
\hline 1.67 & 30 & 9 & $\mathrm{CP}_{1.67-\mathrm{S}_{30}(9)}$ & 1.39 \\
\hline 1.67 & --- & 11 & $\mathrm{CP}_{1.67}(11)$ & 0.87 \\
\hline 1.67 & -- & 13 & $\mathrm{CP}_{1.67}(13)$ & 1.05 \\
\hline
\end{tabular}

[a] The amount of isolated solid is based on the amount of $\mathrm{CaCl}_{2} \cdot 2 \mathrm{H}_{2} \mathrm{O}$ used for the synthesis, which corresponds to $6.25 \mathrm{mmol}$ for the synthesis with $\mathrm{Ca} / \mathrm{P}$ molar ratio of 1 and $10.44 \mathrm{mmol}$ for the synthesis with $\mathrm{Ca} / \mathrm{P}$ molar ratio of 1.67 .

We have investigated the effects of the synthetic conditions such as $\mathrm{Ca} / \mathrm{P}$ molar ratio, the surfactant concentration and the initial $\mathrm{pH}$ of the synthesis on the formation of lamellar mesostructured CaPs. An exhaustive characterization of the materials obtained has been performed to determine the experimental parameters to obtain a novel hybrid material consisting of mesostructured apatite as a pure $\mathrm{CaP}$ phase containing the less amount of organic surfactant. Subsequently, in vitro studies with two representative hybrids have been performed in contact with human osteoblast cell line to assess their biocompatibility regarding potential applications in the field of drug delivery.

\section{Results and Discussion}

Sample names of the CaP materials studied in this work follow the code $\mathrm{CP}_{\mathrm{x}}-\mathrm{S}_{\mathrm{y}}$, where $\mathrm{CP}_{\mathrm{x}}$ indicates the $\mathrm{Ca} / \mathrm{P}$ molar ratio used in the synthesis, 1 or $1.67, S_{y}$ indicates the concentration of SDBS surfactant, ranging from 15 to $90 \mathrm{mM}$ and, in the case of samples obtained with an initial basic $\mathrm{pH}(9,11$ or 13$)$, the $\mathrm{pH}$ value is added between brackets at the end of the code. Sample codes are given in Table 1 together with the experimental conditions used for the syntheses. 
Table 2. Organic content and sulphur composition from thermogravimetric and elemental analysis of materials prepared in this work.

\begin{tabular}{|c|c|c|c|c|c|c|}
\hline Sample & $\begin{array}{l}\text { Theor. } \\
\text { Org. } \\
\text { (wt\%) [a] }\end{array}$ & $\begin{array}{l}\text { Org. } \\
\text { content } \\
(w t \%)^{[b]}\end{array}$ & $\% \mathrm{C}$ & $\% S$ & $\% \mathrm{~S}^{[c]}$ & $\% S^{[d]}$ \\
\hline $\mathrm{CP}_{1}-\mathrm{S}_{15}$ & 19.6 & 11.9 & 5.2 & 0.5 & & \\
\hline $\mathrm{CP}_{1}-\mathrm{S}_{30}$ & 32.7 & 27.1 & 26.2 & 1.6 & & \\
\hline $\mathrm{CP}_{1}-\mathrm{S}_{45}$ & 42.9 & 39.4 & 28.1 & 3.1 & 2.6 & 1.2 \\
\hline $\mathrm{CP}_{1}-\mathrm{S}_{60}$ & 49.3 & 39.3 & 27.9 & 3.1 & & \\
\hline $\mathrm{CP}_{1}-\mathrm{S}_{90}$ & 59.3 & 35.6 & 26.3 & 2.6 & & \\
\hline $\mathrm{CP}_{1.67-\mathrm{S}_{15}}$ & 8.0 & 14.6 & 7.7 & 1.0 & & \\
\hline $\mathrm{CP}_{1.67}-\mathrm{S}_{30}$ & 14.3 & 26.1 & 17.9 & 2.8 & 2.8 & 1.3 \\
\hline $\mathrm{CP}_{1.67}-\mathrm{S}_{45}$ & 20.0 & 35.8 & 22.2 & 3.2 & & \\
\hline $\mathrm{CP}_{1.67}-\mathrm{S}_{60}$ & 25.0 & 39.8 & 27.2 & 3.1 & & \\
\hline $\mathrm{CP}_{1}-\mathrm{S}_{30}(9)$ & 32.7 & 2.6 & 0.5 & $\approx 0$ & & \\
\hline $\mathrm{CP}_{1.67-\mathrm{S}_{15}(9)}$ & 8.0 & 8.0 & 5.1 & 0.5 & & \\
\hline $\mathrm{CP}_{1.67-\mathrm{S}_{30}(9)}$ & 14.3 & 9.4 & 6.5 & 0.5 & & \\
\hline
\end{tabular}

[a] Theoretical organic content is calculated for a pure hydroxyapatite phase in the case of $\mathrm{Ca} / \mathrm{P}=1.67$ molar ratio $\left(10 \mathrm{CaCl}_{2} .2 \mathrm{H}_{2} \mathrm{O}+6 \mathrm{Na}_{2} \mathrm{HPO}_{4} .2 \mathrm{H}_{2} \mathrm{O}+\right.$ $\left.8 \mathrm{NaOH} \rightarrow \mathrm{Ca}_{10}\left(\mathrm{PO}_{4}\right)_{6}(\mathrm{OH})_{2}+20 \mathrm{NaCl}\right)$ and a pure brushite phase in the case of $\mathrm{Ca} / \mathrm{P}=1$ molar ratio $\left(\mathrm{CaCl}_{2} \cdot 2 \mathrm{H}_{2} \mathrm{O}+\mathrm{Na}_{2} \mathrm{HPO}_{4} \cdot 2 \mathrm{H}_{2} \mathrm{O} \rightarrow \mathrm{Ca}\left(\mathrm{HPO}_{4}\right) \cdot 2 \mathrm{H}_{2} \mathrm{O}+\right.$ $2 \mathrm{NaCl})$. [b] Organic content (wt\%) is determined from the TGA weight losses in the range $225-800{ }^{\circ} \mathrm{C}$, i.e., excluding the weight loss due to the desorption of physisorbed water (up to $125^{\circ} \mathrm{C}$ ) as well as crystalline water (up to $225^{\circ} \mathrm{C}$ ) [c] Sulfur content after exahustive water washing. [d] Sulfur content after inmersion in cell culture medium for 24 hours and water washing.

\section{Samples prepared without initial pH control}

The organic content of the hybrid materials was determined from thermogravimetric analyses and the elemental composition was measured to follow the incorporation of SDBS surfactant via sulphur content in the samples (Table 2). TGA and DTA curves registered for materials obtained with $\mathrm{Ca} / \mathrm{P}$ molar ratio of 1 are shown in Figure $1 \mathrm{~A}$ as representative examples. With the aim of better identify the different stages in the weight loss process, the first derivative of the TGA plots have been calculated and are shown in Figure 1B. ${ }^{[47,48]} \mathrm{A}$ sharp weight loss is registered around $200{ }^{\circ} \mathrm{C}$ for the samples prepared with the lower surfactant concentration $\left(\mathrm{CP}_{1}-\mathrm{S}_{15}\right.$ and $\left.\mathrm{CP}_{1.67}-\mathrm{S}_{15}\right)$ being this process attributed to the phase transition of brushite to monetite, which implies the loss of two water molecules in the crystal lattice of brushite giving an endothermic peak in the DTA curve. For all the samples the weight loss due to surfactant combustion is observed around $350{ }^{\circ} \mathrm{C}$ associated with exothermic processes in the DTA.
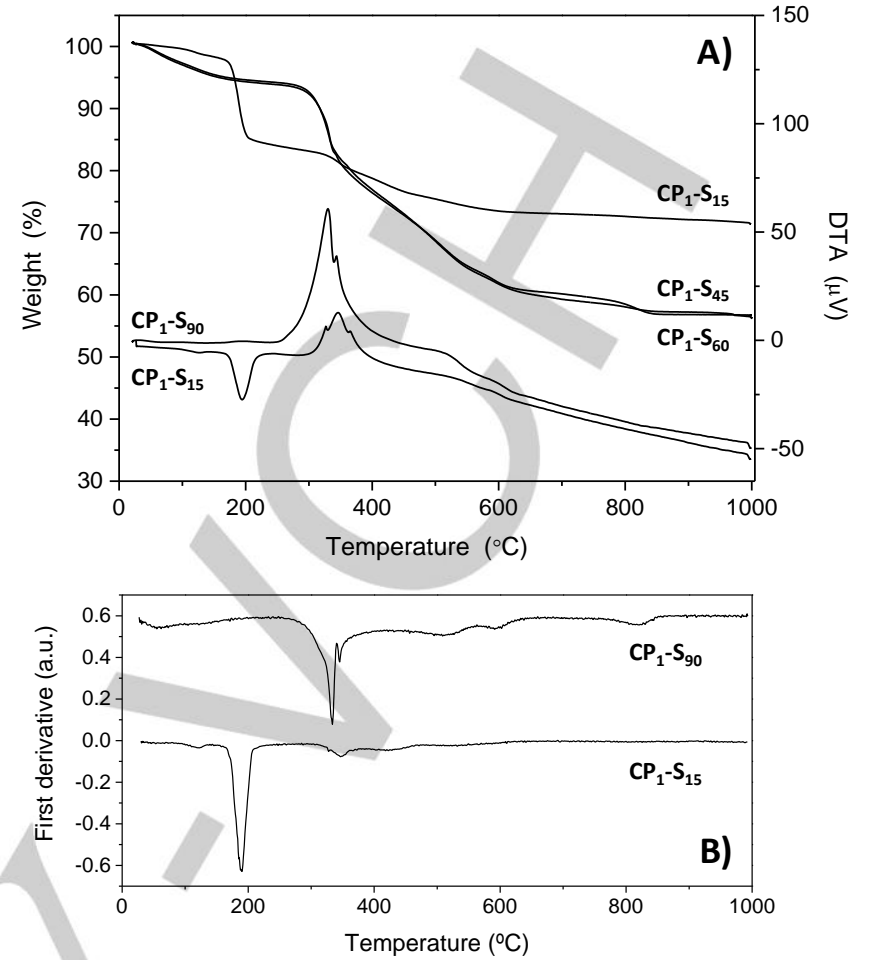

Figure 1. A) Thermogravimetric and differential thermal analysis curves for hybrid materials obtained with molar ratio $\mathrm{Ca} / \mathrm{P}=1$. B) First derivative of the TG curves.

As expected, an increase in the organic matter is found when the SDBS concentration is raised in the synthesis. However, there is no significant difference in the amount of organic matter incorporated in the materials for the higher surfactant concentrations, also being some TGA curves almost coincident in such cases. This fact reflects an upper limit on surfactant incorporation.

In addition, to assess the stability of the hybrid materials in aqueous media, $\mathrm{CP}_{1.67}-\mathrm{S}_{30}$ and $\mathrm{CP}_{1}-\mathrm{S}_{45}$ were subjected to an exhaustive washing with water, that is, twice as long as the protocol established for all samples, and the chemical composition was then analyzed (Table 2). Organic content, as well as carbon and sulphur percentages, remains almost constant for $\mathrm{CP}_{1.67}-\mathrm{S}_{30}$, indicating that, in principle, there is no a release of the surfactant from the materials in aqueous media. However, for sample $\mathrm{CP}_{1}-\mathrm{S}_{45}$ which possesses higher surfactant content, the sulphur percentage still somewhat decreases and casts doubt on the stability of the material in the culture medium regarding the in vitro assays.

FTIR spectrum of $\mathrm{CP}_{1}-\mathrm{S}_{15}$ shows typical brushite bands, while spectra of the materials with $\mathrm{Ca} / \mathrm{P}$ molar ratio 1 obtained with higher SDBS concentrations are compatible with a characteristic HA-like FTIR spectrum (See Figure SI.1 and a FTIR discussion in Supporting Information). These results are consistent with the above commented TGA, in which only $\mathrm{CP}_{1-}$ $\mathrm{S}_{15}$ presents a weight loss and endothermic process associated to crystalline water from brushite. The same pattern was also 
found for the hybrid materials with $\mathrm{Ca} / \mathrm{P}$ molar ratio 1.67 . The bands corresponding to the $v(\mathrm{CH})$ of the surfactant present in the hybrid materials, arond $2900 \mathrm{~cm}^{-1}$, are observed with increasing intensity as the SDBS concentration is raised in the synthesis.

Powder X-ray diffraction patterns obtained from hybrid materials prepared with a molar $\mathrm{Ca} / \mathrm{P}$ ratio of 1 and different SDBS surfactant concentrations are shown in Figure 2. The low angle region shows a single shoulder-like broad diffraction peak at around $2 \theta=2^{\circ}$ in all the samples except for the sample prepared with the lower concentration of SDBS where there is not a clear shoulder at this angle. With this single X-ray maximum as the only evidence, it is not possible to ascertain the existence of a mesostructured arrangement, but its presence could be associated to a disordered mesostructure such as worm-like or pseudolamellar structure. In this hypothesis, this weak reflection would be consistent with a kind of discontinuous lamellar mesostructure and would correspond to its (100) reflection at $4.4 \mathrm{~nm}$ of $d$-spacing.

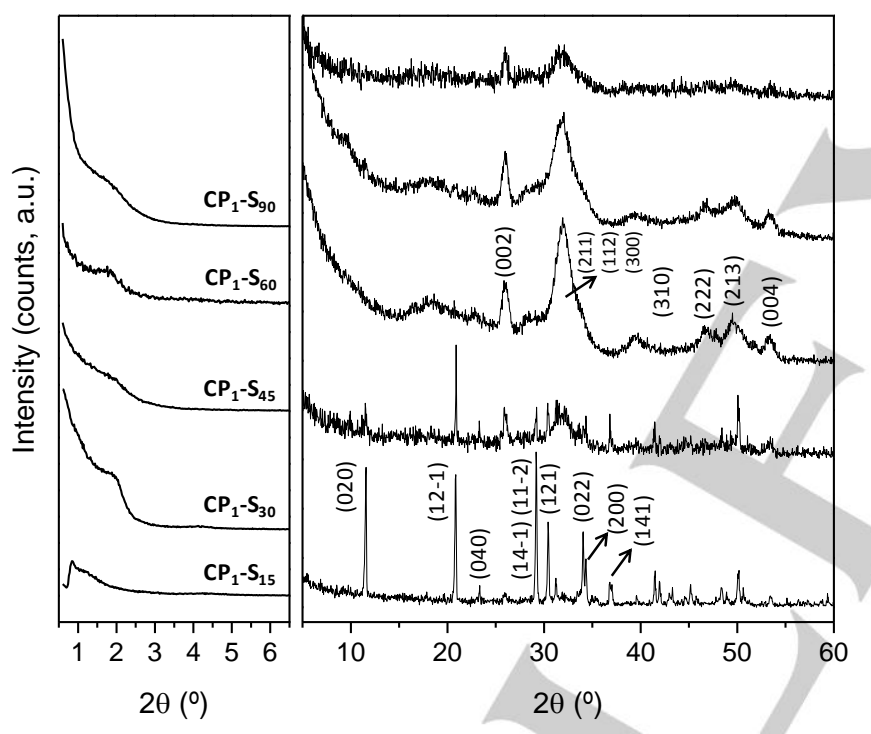

Figure 2. Powder X-ray diffraction patterns of hybrid materials obtained with molar ratio $\mathrm{Ca} / \mathrm{P}=1$ and different surfactant concentrations registered in the low (left) and high (right) angle regions. Reflections of brushite are indexed in the $C_{1}-S_{15} X R D$ pattern and those for hydroxyapatite are indicated in the $\mathrm{CP}_{1}-\mathrm{S}_{45}$ pattern.

The high angle XRD region shows the diffraction pattern due to the CaP phases and the reflections confirm the previous findings obtained by TGA and FTIR. Sample prepared with the lower SDBS concentration $\mathrm{CP}_{1}-\mathrm{S}_{15}$ displays the characteristic maxima of brushite and, as the surfactant concentration increases, a mixture of brushite-apatite is found in $\mathrm{CP}_{1}-\mathrm{S}_{30}$ hybrid. The typical reflections of apatite phase appear from the material prepared with $45 \mathrm{mM}$ of SDBS, i.e., samples $\mathrm{CP}_{1}-\mathrm{S}_{60}$ and $\mathrm{CP}_{1}-\mathrm{S}_{90}$. For these two latter samples, all diffraction peaks can be indexed to a hexagonal apatite (PDF 09-0432). The broadness of the maxima indicates that nanocrystalline apatite has been obtained, as later proved by TEM images.

In an attempt to obtain mainly an apatite phase, another series of hybrid materials was prepared in the same conditions but using a $\mathrm{Ca} / \mathrm{P}$ molar ratio of 1.67 which is the stoichiometric ratio for hydroxyapatite.

In the low angle XRD region, hybrid materials prepared with the $\mathrm{Ca} / \mathrm{P}$ molar ratio of 1.67 also show a shoulder at $2 \theta=2^{\circ}$, although quite more defined that the signal for materials with $\mathrm{Ca} / \mathrm{P}$ of 1 (Figure 3 , left). For this series of hybrid materials, again the sample prepared with the lower SDBS concentration seems to lack of any kind of mesostructure. Although the $\mathrm{Ca} / \mathrm{P}$ molar ratio of 1.67 would be more appropriated for obtaining apatite phases, from the analysis of the high angle region (Figure 3, right) it can be observed that a nanoapatite phase is only achieved with a high SDBS concentration, only $\mathrm{CP}_{1.67}-\mathrm{S}_{60}$ contains apatite as the only CaP phase. Hybrids prepared with lower SDBS concentration still present a mixture of apatite and brushite and pure brushite is found for $\mathrm{CP}_{1.67}-\mathrm{S}_{15}$, the sample prepared with the lowest surfactant concentration. These samples have been prepared without an initial control of the $\mathrm{pH}$, i.e., the $\mathrm{pH}$ value has not been fixed to a basic value at the beginning of the synthesis. Therefore, the $\mathrm{HPO}_{4}{ }^{2-}$ is the most abundant specie in the acid-base equilibrium, leading to the formation of brushite $\left(\mathrm{CaHPO}_{4} \cdot 2 \mathrm{H}_{2} \mathrm{O}\right)$ even though the $\mathrm{Ca} / \mathrm{P}$ molar ratio in the reaction medium is the suitable one for an apatite phase which contains the deprotonated $\mathrm{PO}_{4}{ }^{3-}$ anion.

Hence, a common fact in both series of hybrid materials prepared without an initial control of the $\mathrm{pH}(\mathrm{Ca} / \mathrm{P}=1$ and $\mathrm{Ca} / \mathrm{P}$ $=1.67$ ) is that a pure brushite phase is found for the samples prepared with the lower surfactant concentration. Also for both series, as the SDBS concentration increases apatite maxima start to show up in the XRD patterns, therefore a phase mixture of apatite and brushite is identified. Then, for the higher SDBS concentrations pure nanocrystalline apatite phases are identified. Thus, there is a threshold value at which the obtained CaP phase is apatite. The pure apatite phase is found for $45 \mathrm{mM}$ and higher concentrations in the materials prepared with $\mathrm{Ca} / \mathrm{P}$ molar ratio of 1 , and for $60 \mathrm{mM}$ and onwards in the serie 1.67.

Then, as it is revealed by the characterization data, the apatite phase is more favourable as the SDBS concentration increases in the synthesis, although, as expected, $\mathrm{pH}$ variations in the two different steps of the synthesis, before and after the addition of the $\mathrm{Ca}^{2+}$ solution, as the SDBS concentration increases were not found. The protonation of sulphonate polar heads of the SDBS in the hydrogenphosphate aqueous solution, increasing the initial $\mathrm{pH}$ value of the medium, is discarded because sulfonic acids are strong acids (for example, the $\mathrm{pK}_{\mathrm{a}}$ value of $p$-toluene sulfonic acid is -2.8$) \cdot{ }^{[49,50]}$ Anyhow, the $\mathrm{pH}$ measurements that were performed during the syntheses confirmed this fact. Before the addition of the $\mathrm{Ca}^{2+}$ source $\mathrm{pH}$ values of ca. 8 were registered for all the samples prepared without initial $\mathrm{pH}$ control, independenly of the SDBS 
concentration. The $\mathrm{pH}$ values after the addition of the $\mathrm{Ca}^{2+}$ source showed a decrease to ca. 5 for the samples prepared without inital $\mathrm{pH}$ control, and to ca. 6 for the samples prepared at the initial $\mathrm{pH}$ of 9 .

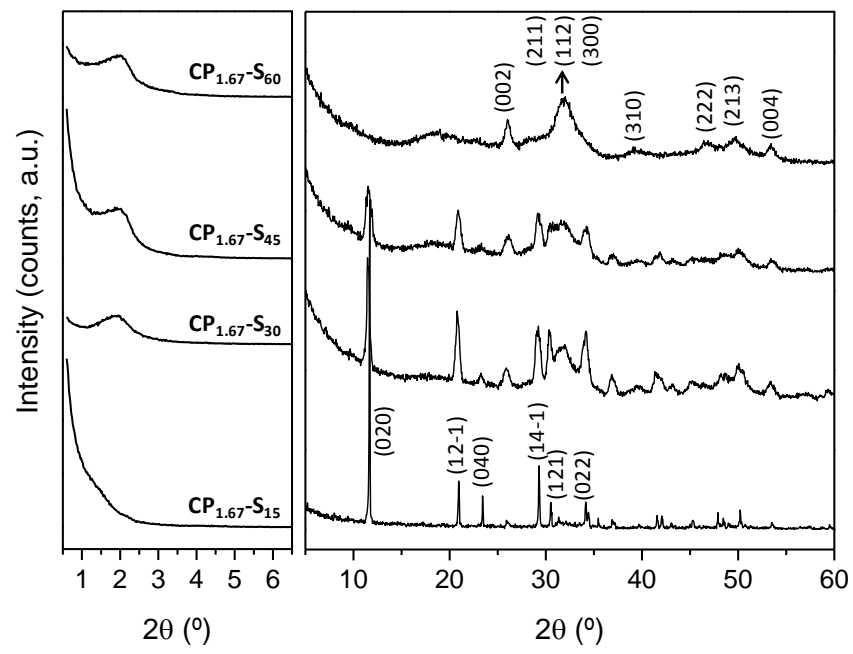

Figure 3. Powder X-ray diffraction patterns of hybrid materials obtained with molar ratio $\mathrm{Ca} / \mathrm{P}=1.67$ and different surfactant concentration registered in the low (left) and high (right) angle regions. Reflections for brushite phase are indexed in the $\mathrm{CP}_{1.67-\mathrm{S}_{15}} \mathrm{XRD}$ pattern and those for hydroxyapatite are indicated in the $\mathrm{CP}_{1.67}-\mathrm{S}_{60}$ pattern.

A ${ }^{31} \mathrm{P}$ solid state NMR study as a function of the surfactant concentration has been also performed to complement the results obtained from FTIR and DRX analysis. Figure 4 shows a comparison between ${ }^{31} \mathrm{P}$ MAS NMR spectra for hybrid materials prepared with a $\mathrm{Ca} / \mathrm{P}$ molar ratio of 1.67 and also the spectra obtained with the cross-polarized technique ${ }^{31} \mathrm{P}$ CP MAS NMR. As expected, only resonances for the phosphorous $q^{0}$ environment, i.e., orthophosphate group, appear. The signals are due to the presence of the $\mathrm{PO}_{4}{ }^{3-}$ and the $\mathrm{HPO}_{4}{ }^{2-}$ anions from apatite-like and brushite phases. The CP experiments uses cross-polarization from the nearby protons and yield unquantitative experiments, but allows to ascribe the upfield resonance in the MAS NMR to a protonated phosphate in the inorganic phase since it suffers from cross-polarization enhancement in the CP MAS NMR. Therefore, the resonance around $0.2 \mathrm{ppm}$ can be assigned to the $\mathrm{HPO}_{4}{ }^{2-}\left(\mathrm{q}_{2}{ }_{2}\right)$ environment since it is affected by nearby protons and the downfield signal around $1.7 \mathrm{ppm}$ corresponds to the $\mathrm{PO}_{4}{ }^{3-}\left(\mathrm{q}^{0}{ }_{1}\right)$ anion. Table 3 shows the chemical shifts and populations of the phosphorous $q^{0}$ environments from the ${ }^{31} \mathrm{P}$ MAS NMR spectra. As the surfactant concentration used in the synthesis increases the formation of a brushite phase, then a mixture of both brushite and apatite phases and finally pure apatite-like phase takes place as confirmed by XRD. In this line the $\mathrm{q}^{0}{ }_{1}\left(\mathrm{PO}_{4}{ }^{3-}\right)$ population is majority for the sample prepared with the lowest surfactant concentration and the $\mathrm{q}_{2}^{0}\left(\mathrm{HPO}_{4}{ }^{2-}\right)$ population is majority for the sample prepared with the highest surfactant concentration, therefore reflecting a general trend of decreasing the $q_{2}^{0} / q^{0}{ }_{1}$ ratio. Besides, the resonance from the $\mathrm{HPO}_{4}{ }^{2-}\left(q^{0}{ }_{2}\right)$ environment is also present in the spectra of $\mathrm{CP}_{1.67}-\mathrm{S}_{60}$, which has been identified as pure apatite-like phase. This fact could be explained with the obtaining of a calcium deficient apatite, so the $\mathrm{HPO}_{4}{ }^{2-}$ anion is present to balance the charge. This circumstance, also corroborated with the EDX analysis (Table 4), would also explain anomalous values for the intermediate samples which can contain the $\mathrm{HPO}_{4}{ }^{2-}$ anion from the brushite phase as well as from the calcium deficient apatite. Regarding the ${ }^{31} \mathrm{P}$ CP MAS NMR spectra (Figure 4, right), the signal intensities have been generally enhanced with respect to the corresponding MAS NMR spectra. This fact can be explained because the CP technique enhances the signal intensities in all the spectra that contains brushite since the phosphorous nuclei are more affected by the presence of $\mathrm{H}_{2} \mathrm{O}$ molecules on the crystal lattice of the brushite. The less affected spectrum is for the $\mathrm{CP}_{1.67}-\mathrm{S}_{60}$ hybrid material which is coherent with the presence of a unique apatite-like phase, as it was identified in the XRD pattern.

The possibility of calcium phosphate regions in strong interaction with the sulfonate heads of the surfactant which would give different phosphorous environments, and therefore different resonances for the same anion, cannot be discarded for these hybrid materials. In fact, materials $\mathrm{CP}_{1.67}-\mathrm{S}_{15}$ and $\mathrm{CP}_{1.67}-\mathrm{S}_{60}$, ascribed to brushite or apatite-like phases from XRD, exhibit two resonances and also the intermediate materials $\mathrm{CP}_{1.67}-\mathrm{S}_{30}$ and $\mathrm{CP}_{1.67}-\mathrm{S}_{45}$ show anomalous values for the $\mathrm{q}^{0}{ }_{2} / \mathrm{q}^{0}{ }_{1}$ ratio. Multinuclear and homonuclear ${ }^{31} \mathrm{P}$ 2D MAS NMR studies would be complementary to assess whether the two possibilities are taking place simultaneously.

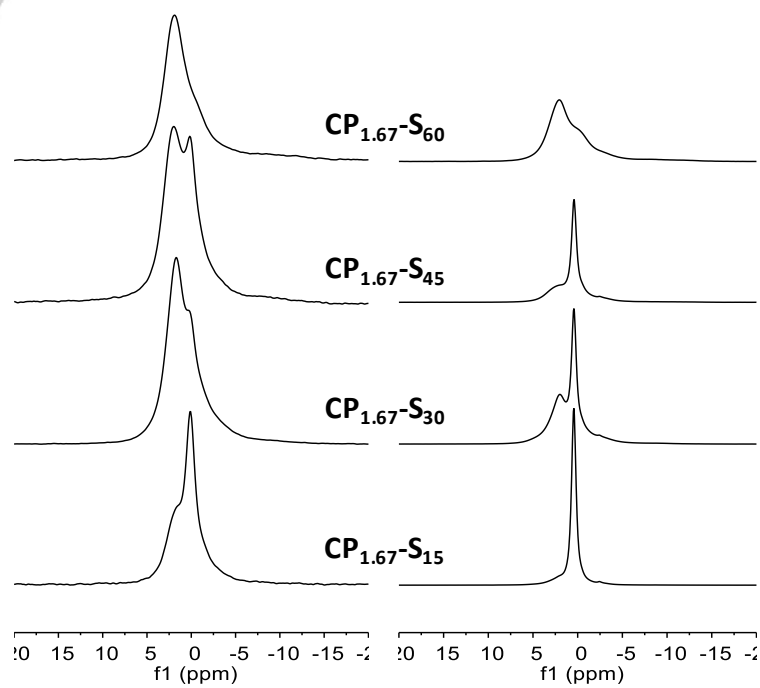

Figure 4. ${ }^{31} \mathrm{P}$ MAS NMR spectra (left) and ${ }^{31} \mathrm{P}$ CP MAS NMR spectra (right) of $\mathrm{CP}_{1.67} \mathrm{~S}_{\mathrm{x}}$ hybrid materials. Intensity scales for CP MAS NMR spectra are one order of magnitude higher than those of MAS NMR spectra (not drawn to scale). 
Table 3. Chemical shifts, populations (\%) and peak area relations of the phosphorous $q^{0}$ environments on the basis of the deconvolution of ${ }^{31} \mathrm{P}$ MAS

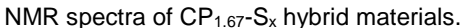

\begin{tabular}{llll}
\hline Sample & \multicolumn{3}{c}{$\delta$, ppm (peak area, \%) } \\
\hline & $\mathbf{q}^{0}{ }_{1}\left(\mathrm{PO}_{4}{ }^{3-}\right)$ & $\mathbf{q}^{0}{ }\left(\mathrm{HPO}_{4}{ }^{2-}\right)$ & $\mathbf{q}^{0} / \mathbf{q}^{0}{ }_{1}$ \\
$\mathbf{C P}_{1.67}-\mathbf{S}_{15}$ & $1.6(39)$ & $0.1(61)$ & 1.56 \\
$\mathbf{C P}_{1.67-\mathbf{S}_{30}}$ & $1.7(72)$ & $0.2(28)$ & 0.39 \\
$\mathbf{C P}_{1.67-\mathbf{S}_{45}}$ & $2.0(51)$ & $0.2(49)$ & 0.96 \\
$\mathbf{C P}_{1.67}-\mathbf{S}_{60}$ & $1.9(83)$ & $-0.5(17)$ & 0.20
\end{tabular}

Figure 5 shows TEM images of hybrid materials of the series $\mathrm{Ca} / \mathrm{P}=1$ and $\mathrm{Ca} / \mathrm{P}=1.67$, respectively. For both series, micrographs at lower magnifications (Figure 5, upper row) show an open structure of large and homogeneous aggregates composed by entanglements of nanoplates. At higher magnifications, it can be observed that the nanoplates are randomly distributed in bundles and their dimensions fall in the range of the biological CaPs. ${ }^{[51]} \mathrm{A}$ lamellar mesostructure can be identified taking into account that the dark areas represent high electron density regions, which would correspond to the inorganic CaP phase, and the intermediate light areas would depict the interlayer regions occupied by the surfactant hydrocarbon tails.

The distance comprising two layers, i.e., one inorganic plus one organic layer, is around $2.5 \mathrm{~nm}$, somehow homogeneous for all the regions where mesostructure is clearly observed, although it is not a precise repetitive distance. This fact, together with the point that layer repetition seems to be between ca. 3-4 layers up to 10 layers as maximum reiteration for all the samples, explains the absence of a clear diffraction maximum in the XRD patterns of the hybrid materials registered in the low angle region. The broad maximum around $2 \circ$ would be a reflection of this kind of formation that can be described as a discontinuous lamellar mesophase, where a range of repetitive distances around $2.5 \mathrm{~nm}$ is found. Another peculiarity of this mesostructure is that it is kind of wavy. To explain the curvature of the layers we can take into account the size of the polar head of the surfactant SDBS compared to SDS. Regarding CaPs, the SDS surfactant only gives lamellar mesophases composed of right multilayers. ${ }^{[4]}$ The SDBS surfactant possesses a benzene moiety adjacent to the sulfonate group and this makes a bigger polar head than in SDS. Probably this factor induces a curvature in the attaining of the parallel arrangement of nanoplates, therefore modifying the mesophase towards an undulating structure.
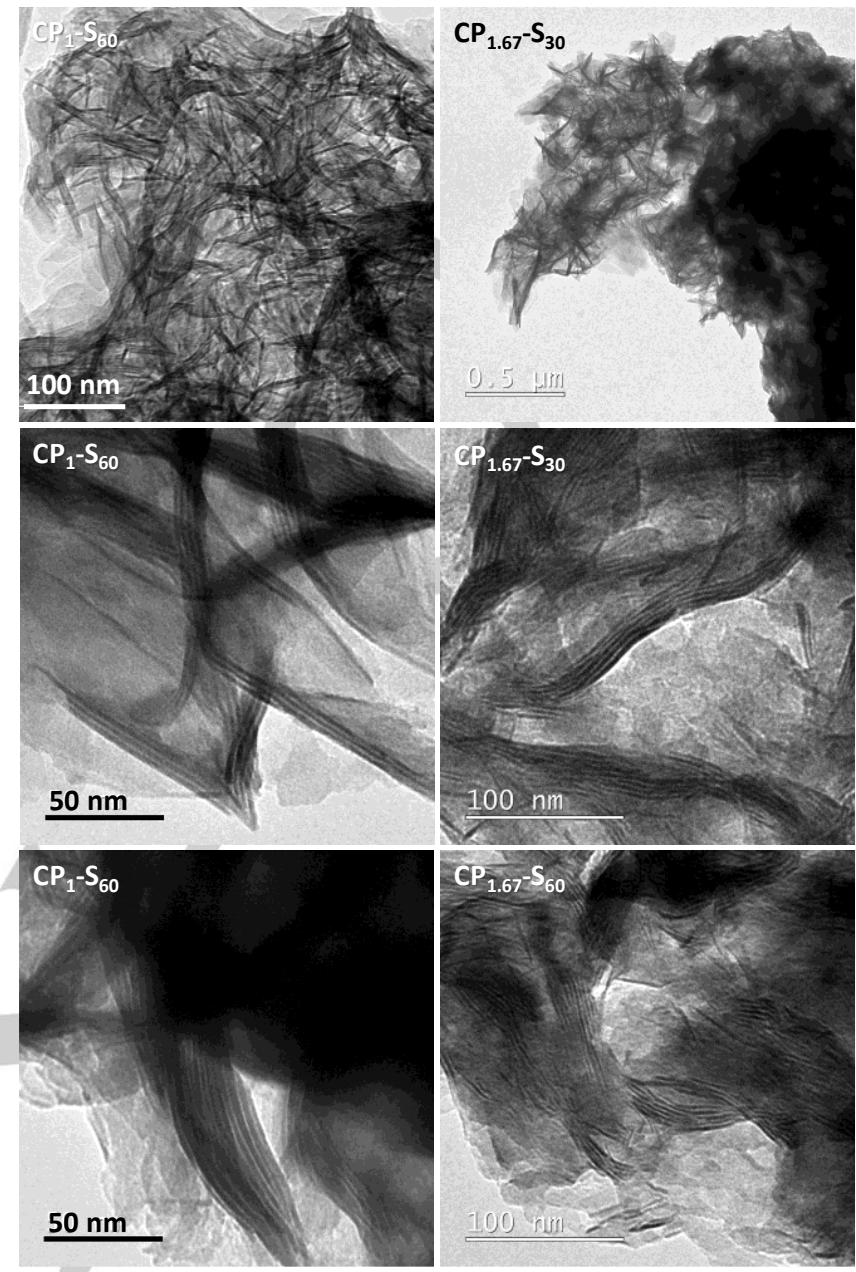

Figure 5. TEM micrographs of $\mathrm{CaP}$ hybrid materials obtained with $\mathrm{Ca} / \mathrm{P}$ molar ratio 1 in the presence of $60 \mathrm{mM}$ of SDBS (left column) and CaP hybrid materials obtained with $\mathrm{Ca} / \mathrm{P}$ molar ratio 1.67 in the presence of 30 and 60 $\mathrm{mM}$ of SDBS (right column).

For both series, the mesolamellar arrangements of nanoplates observed in samples prepared with higher surfactant concentration are larger and possess more repetitive layers than those found in the hybrid materials obtained with lower SDBS concentrations. Nevertheless, the same mesostructure can be also found in samples prepared with the lower SDBS concentration, i.e., $15 \mathrm{mM}$ (see Figure SI.3 in Supporting Information for sample $\mathrm{CP}_{1.67}-\mathrm{S}_{15}$ ). In any case, for all the samples the presence of different types of particles is discarded. The morphology of the hybrid $\mathrm{CaP}$ particles consist of nanoplates that possess the composition of the CaP identified in the high angle region of the $\mathrm{XRD}$, i.e., brushite, mixture of brushite and apatite, and apatite. To assess that, energy dispersive X-ray analyses (Table 4) were performed in different regions of the samples, i.e., regions where a clear mesostructure is observed, regions with no observed mesostructure and large areas comprising both. 
Table 4. $\mathrm{Ca} / \mathrm{S}$ and $\mathrm{Ca} / \mathrm{P}$ molar ratios obtained from energy dispersive $\mathrm{X}$-ray analysis.

\begin{tabular}{|c|c|c|c|c|}
\hline Sample & $\mathrm{Ca} / \mathrm{S}$ & $\mathrm{Ca} / \mathbf{S}^{\text {[a] }}$ & $\mathrm{Ca} / \mathbf{S}^{[b]}$ & $\mathrm{Ca} / \mathrm{P}$ \\
\hline $\mathrm{CP}_{1}-\mathrm{S}_{45}$ & 5.89 & & & 1.31 \\
\hline $\mathrm{CP}_{1}-\mathrm{S}_{60}$ & 6.68 & & & 1.26 \\
\hline $\mathrm{CP}_{1.67}-\mathrm{S}_{15}$ & 11.71 & 18.10 & 14.23 & 1.24 \\
\hline $\mathrm{CP}_{1.67}-\mathrm{S}_{30}$ & 7.34 & 8.47 & 6.65 & 1.23 \\
\hline $\mathrm{CP}_{1.67}-\mathrm{S}_{60}$ & 5.87 & & & 1.21 \\
\hline
\end{tabular}

[a] EDX analysis performed in areas where lamellar mesostructure is clearly observed. [b] EDX analysis performed in areas corresponding to plaques and without observed mesostructure.

The EDX data confirm a comparable content in S, since the $\mathrm{Ca} / \mathrm{S}$ molar ratios present very similar values in all the regions. The areas where a lamellar mesostructure is clearly observed are composed of superposed or stacked plates in parallel and seen in a cross section. Therefore, the regions where no mesostructure is observed can correspond to a perpendicular view to the plates. These regions would also be composed by several plates stacked with their surfactant interlayers, perhaps in a smaller number of stacked plates. Regarding the $\mathrm{Ca} / \mathrm{P}$ molar ratios, the obtained values are around 1.25 which is lower than the theoretical value of 1.67 for stoichiometric hydroxyapatite. These values would reflect a calcium deficient apatite for samples which possess an XRD pattern of poorly crystallized or nanometric apatite phase and it is also coherent with the coexistence of brushite $(\mathrm{Ca} / \mathrm{P}=1)$ and apatite-like phases in some of the samples investigated.

As expected, a strong electrostatic interaction between calcium ions and the sulfonate group of the polar head of SDBS surfactant is produced. The solubility product of calcium alkylsulfonates is very low, ${ }^{[52]}$ for example, $K_{p s}=1.5 \times 10^{-13}$ for a $\mathrm{C}_{14}$ hydrocarbon chain benzenesulfonate, ${ }^{[53]}$ and therefore, the addition of a $\mathrm{Ca}^{2+}$ solution over a SDBS aqueous solution produces an immediate precipitate. On the other hand, the concentrations of SDBS surfactant used in this work are higher than the critical micellar concentration (CMC) of SDBS in pure water $\left([\mathrm{SDBS}]_{\mathrm{cmc}}\left(\mathrm{H}_{2} \mathrm{O}\right)=1.2 \times 10^{-3} \mathrm{M}\right) .^{[54]}$ As mentioned above, the mesolamellar formation could be found under TEM observation even in the hybrid materials prepared with the lower surfactant concentration (see Figure SI.3 in Supporting Information for $\mathrm{CP}_{1.67}-\mathrm{S}_{15}$ ), therefore indicating that SDBS selfassembles to a lamellar mesostructure for all the conditions studied. Then, the results suggest that the affinity of the sulfonate in the surfactant for $\mathrm{Ca}^{2+}$ ions induces the precipitation of a $\mathrm{Ca}(\mathrm{SDBS})_{2}$ aggregate with the capability to control the nucleation process in a first stage. This $\mathrm{Ca}(\mathrm{SDBS})_{2}$ aggregate would act as substrate for a fast nucleation and growth of $\mathrm{CaP}$ nanocrystals nearby, i.e., in layered morphology or platelets. The same mechanism has been reported for surfactants with phosphonate groups in the polar head. ${ }^{[35,36]}$ As well, similar effects have been reported when sulfonated polymeric additives are used during $\mathrm{CaCO}_{3}$ mineralization, being the sulfonate-Ca complex the primary species in solution, therefore acting as a nucleation agent. ${ }^{[55-57]} \mathrm{A}$ schematic representation of the proposed lamellar formation induced by the SDBS presence during the $\mathrm{CaP}$ precipitation is shown in Figure 6. This mechanism is also consistent with the formation of calcium deficient apatite phases, because in the presence of surfactant the formation of the $\mathrm{Ca}(\mathrm{SDBS})_{2}$ aggregates would withdraw $\mathrm{Ca}^{2+}$ from the solution in the first stage, ${ }^{[56,57]}$ therefore obtaining materials with $\mathrm{Ca} / \mathrm{P}$ molar ratios lower than 1.67 even in the samples where the stoichiometric ratio has been used during their synthesis (see Table 4).

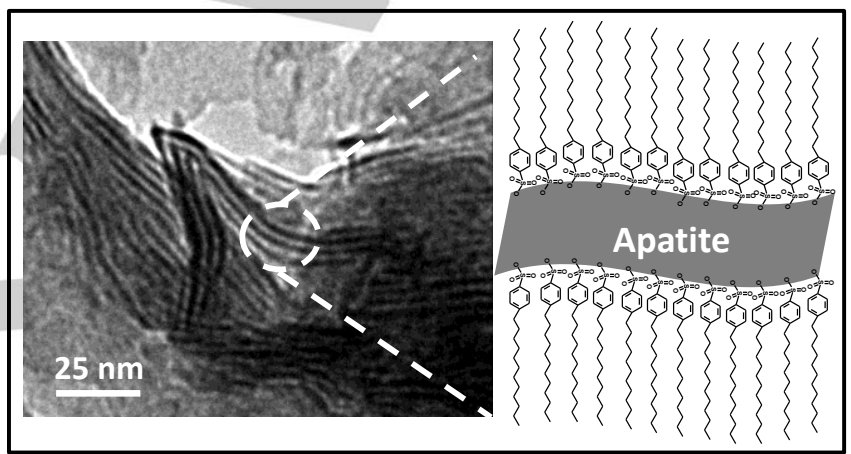

Figure 6. TEM image of lamellar structure in the hybrid materials and schematic representation of the lamellar formation by SDBS presence during CaP precipitation.

\section{Samples synthetized at initial $\mathrm{pH} 9$}

With previous results in mind we tried to produce hybrid materials with apatite as CaP mineral phase possessing lamellar mesoestructure and the minimum possible amount of SDBS. Therefore, taking into account that a basic medium is a more favourable environment to obtain the HA phase, ${ }^{[51]}$ samples with $\mathrm{Ca} / \mathrm{P}$ molar ratio of 1 and 1.67 were synthetized at initial $\mathrm{pH} 9$ in the presence of surfactant concentrations as low as 15 and 30

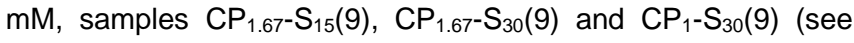
Table 1). At these synthetic conditions, regardless of the $\mathrm{Ca} / \mathrm{P}$ molar ratio, an apatite phase was found for all the samples. XRD patterns in the high angle region correspond with nanocrystalline apatite (Figure 7.B), as well the FTIR spectra are also consistent with apatite phase (Figure 7.C).

However, the organic content for all these samples is negligible (see TG data in Table 2) and the bands due to surfactant molecules are no visible in the FTIR spectra. Only the $\mathrm{CP}_{1.67}-\mathrm{S}_{30}(9)$ material shows incipient bands around $2900 \mathrm{~cm}^{-1}$ from the $v(\mathrm{CH})$ of the methylene groups of SDBS (Figure 7.C), consistent with a slowly higher organic content among these three materials (Table 2). Furthermore, any diffraction maximum 
is found in the low angle region (Figure 7.A). All these evidences point out to that the formation of HA phase in these conditions is so favourable that it precipitates independently of the presence of the surfactant, being any interaction between the inorganic and the organic phase, which is eliminated in the solution during the washing steps. Accordingly with the absence of surfactant, no mesostructure was observed in the TEM images for the samples obtained at basic $\mathrm{pH}$ (Figure 7D and E). The morphology of the particles is needle-like or nanometric plaques or flakes of approximately $100 \mathrm{~nm}$ long and a few nanometers thick, ca. $5 \mathrm{~nm}$, similar to the usual $\mathrm{HA}$ formed by precipitation. ${ }^{[51]}$

\section{Control samples obtained at high pH without surfactant}

Two CaP samples without surfactant were prepared as control materials for the biological experiments. XRD and FTIR characterization of these materials is shown in Figure SI.4 in Supporting Information. To prepare an HA phase, the amount of $\mathrm{NaOH}$ used in the synthesis was the stoichiometric $\left(10 \mathrm{CaCl}_{2} .2 \mathrm{H}_{2} \mathrm{O}+6 \mathrm{Na}_{2} \mathrm{HPO}_{4} \cdot 2 \mathrm{H}_{2} \mathrm{O}+8 \mathrm{NaOH} \rightarrow \mathrm{Ca}_{10}\left(\mathrm{PO}_{4}\right)_{6}(\mathrm{OH})_{2}\right.$ $+20 \mathrm{NaCl}$ ) and the measured $\mathrm{pH}$ before adding the $\mathrm{Ca}^{2+}$ source was 13 . Under these conditions sample $\mathrm{CP}_{1.67}(13)$ was obtained as a pure $\mathrm{HA}$ phase reflecting a XRD pattern typical for an apatite phase with broad diffraction maxima due to nanometric crystal domains. The FTIR spectrum is also consistent with crystalline $\mathrm{HA}$ with bands at 561 and $602 \mathrm{~cm}^{-1}$ for $\delta(\mathrm{OPO})$ of the $\mathrm{PO}_{4}{ }^{3-}$ in a crystalline environment. The second control material was prepared using $25 \%$ of the stoichiometric amount of $\mathrm{NaOH}$, therefore reaching a lower $\mathrm{pH} 11$ before the addition of the $\mathrm{Ca}^{2+}$ source. In this case $\mathrm{CP}_{1.67}(11)$ sample resulted a mixture of $\mathrm{CaP}$ phases as observed in the XRD diffraction pattern, where brushite and apatite are identified. Furthermore, brushite typical absorption bands appear in the FTIR spectrum of this material. As expected, CaP control materials do not show maxima in the low angle region of the XRD pattern. TEM images of these control samples (Figure SI.5A and B in Supporting Information) show particle morphology of plates or plaques ca. $100 \mathrm{~nm}$ long and $50 \mathrm{~nm}$ wide for $\mathrm{CP}_{1.67}(11)$, meanwhile grains of $c a .20-30$ $\mathrm{nm}$ are observed for $\mathrm{CP}_{1.67}(13)$. The electron diffraction pattern of $\mathrm{CP}_{1.67}(13)$ (Figure SI.5C in Supporting Information) evidences the presence of pure nanometric apatite with a $d$-spacing at 0.68 $\mathrm{nm}$ which correspond to the (001) reflection of an apatite-like phase in concordance with the XRD pattern.

\section{In vitro cell culture studies}

Two hybrid materials were selected for the in vitro cell culture studies with human Saos-2 osteoblasts: $\mathrm{CP}_{1}-\mathrm{S}_{45}$, because it exhibits an apatite phase containing the minimum amount of SDBS, and $\mathrm{CP}_{1.67}-\mathrm{S}_{30}$ because, although the inorganic phase is a mixture of brushite and apatite, still contains a lower amount of SBDS. The behavior of these hybrids was compared with control cells cultured either in the absence of materials or in the presence of surfactant free apatite phase $\mathrm{CP}_{1.67}(13)$, surfactant free brushite-apatite phase $\mathrm{CP}_{1.67}(11)$ and pure SDBS surfactant in the same amount present in the assayed hybrids. The hybrid materials conformed into disc pieces by uniaxial pressure were not mechanically stable after immersion in culture medium. For this reason, materials were used as powders for the cell culture assays.
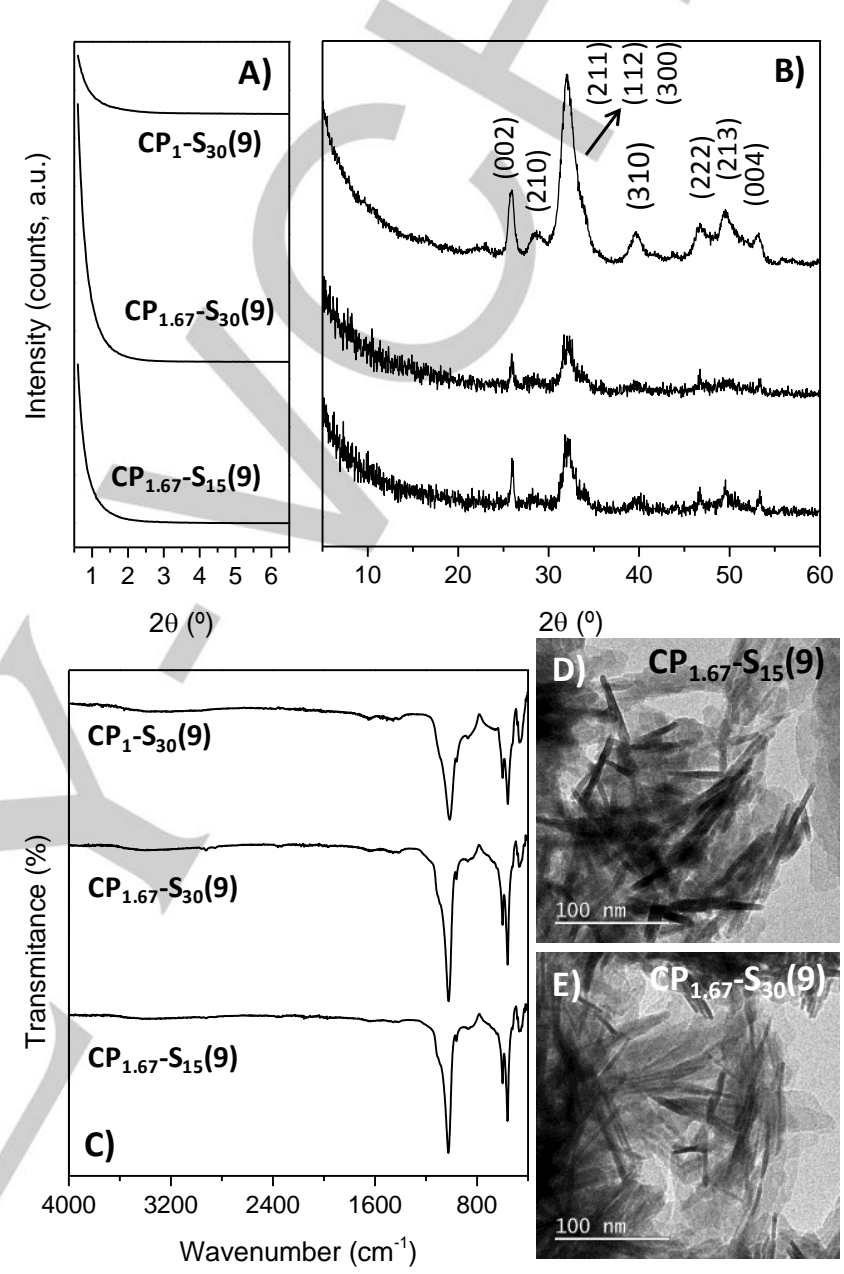

Figure 7. Powder X-ray diffraction patterns of hybrid materials obtained at basic $\mathrm{pH}$ registered in the low $(\mathrm{A})$ and wide $(\mathrm{B})$ angle ranges. Reflections for apatite phase are indexed in the $\mathrm{CP}_{1}-\mathrm{S}_{30}(9)$ XRD pattern. (C) FTIR spectra of hybrid materials. TEM micrographs of $\mathrm{CaP}$ materials obtained with $\mathrm{Ca} / \mathrm{P}$ molar ratio 1.67 and basic $\mathrm{pH}$ in the presence of (D) 15 and (E) $30 \mathrm{mM}$ of SDBS.

Figure 8 shows cell proliferation and viability of human Saos2 osteoblasts, cultured for $24 \mathrm{~h}$ in the presence of each material $\left(1 \mathrm{mg} \mathrm{mL}{ }^{-1}\right.$ ). As observed, $\mathrm{CP}_{1.67}(13)$ did not alter osteoblast proliferation meanwhile $\mathrm{CP}_{1.67}(11), \mathrm{CP}_{1}-\mathrm{S}_{45}$ and $\mathrm{CP}_{1.67}-\mathrm{S}_{30}$ induced significant cell number decreases $(p<0.005)$, more pronounced with the two hybrid materials containing SDBS. However, high viability values were obtained after treatment with all these materials except with $\mathrm{CP}_{1}-\mathrm{S}_{45}$. This material induced plasma membrane damage in osteoblasts which were not able to exclude propidium iodide, as it also occurred in cells treated with SDBS. 

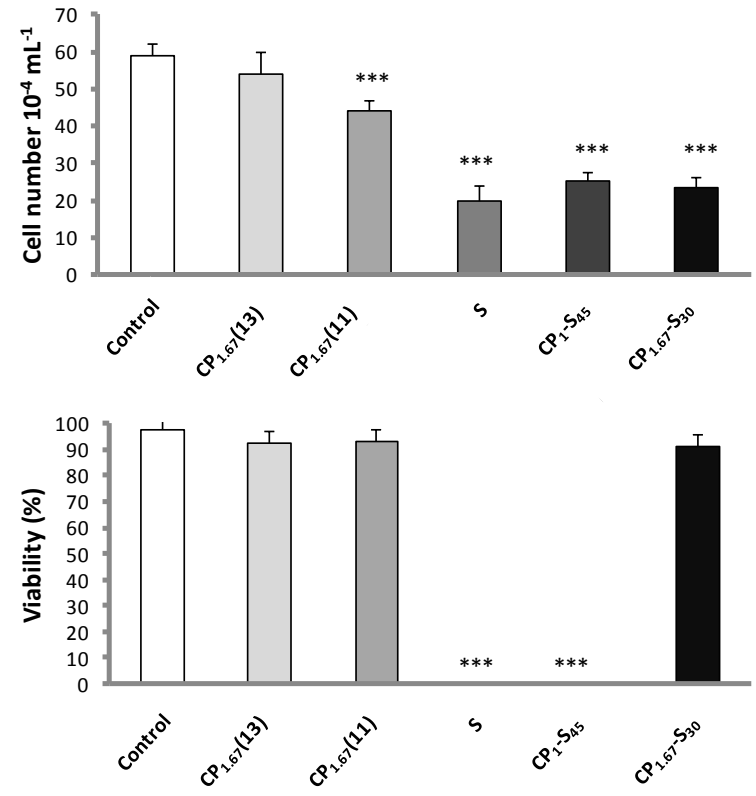

Figure 8. Effects of $1 \mathrm{mg} \mathrm{mL}^{-1}$ of powdered $\mathrm{CP}_{1.67}(13), \mathrm{CP}_{1.67}(11), \mathrm{CP}_{1}-\mathrm{S}_{45}$ and $\mathrm{CP}_{1.67}-\mathrm{S}_{30}$ materials on proliferation and viability of human Saos-2 osteoblasts after 24 hours of treatment. Control = cells cultured without materials. $S=$ cells cultured with SDBS surfactant at the equivalent amount present in the hybrid materials. Statistical significance: ${ }^{* * *} p<0.005$ (compared to control without material).
Since cell proliferation is dependent on the cell cycle progression through the $G_{0} / G_{1}$ phase (Quiescence/Gap ${ }_{1}$ ) to the $S$ phase (Synthesis) and finally to the $G_{2} / M$ phase $\left(G_{a p}\right.$ and Mitosis), the analysis of cell cycle phases and profiles of human Saos-2 osteoblasts cultured for $24 \mathrm{~h}$ in the presence of all these materials was carried out. The SubG1 fraction, corresponding to cells with fragmented DNA, was used as indicative of apoptosis. As it can be observed in Figure 9, no alterations were detected in $G_{0} / G_{1}$ and $S$ phases after treatment with $C_{1.67}(13)$ and $\mathrm{CP}_{1.67}(11)$ materials, which induced slight but significant decreases in the $G_{2} / M$ phase $(p<0.05)$. Moreover, $C P_{1.67}-S_{30}$ did not alter the $G_{0} / G_{1}$ and $G_{2} / M$ phases although produced a slight but significant decrease in the $S$ phase $(p<0.05)$. Concerning $\mathrm{CP}_{1}-\mathrm{S}_{45}$, this material induced pronounced significant decreases in $G_{0} / G_{1}$ and $G_{2} / M$ phases $(p<0.005$ ) and a significant increase of the $S$ phase $(p<0.005)$, evidencing the induction of $S$-phase cell cycle arrest. Although very low levels of apoptosis (SubG1 fraction) were detected with the other materials, $\mathrm{CP}_{1}-\mathrm{S}_{45}$ induced around $50 \%$ of cell death by apoptotic mechanisms. The drastic effects of $\mathrm{CP}_{1}-\mathrm{S}_{45}$ and SDBS surfactant on cell cycle profile of human Saos-2 osteoblasts are shown in Figure SI.6 (see Supporting Information).

\footnotetext{
Figure 9. Effects of $1 \mathrm{mg} \mathrm{mL}^{-1}$ of powdered $\mathrm{CP}_{1.67}(13), \mathrm{CP}_{1.67}(11), \mathrm{CP}_{1}-\mathrm{S}_{45}$ and $\mathrm{CP}_{1.67}-\mathrm{S}_{30}$ materials on cell cycle phases of human Saos-2 osteoblasts after 24 hours of treatment. Control $=$ cells cultured without materials. $S=$ cells cultured with SDBS surfactant at the equivalent amount present in the hybrid materials.

Statistical significance: ${ }^{*} \mathrm{p}<0.05,{ }^{* * *} \mathrm{p}<0.005$ (compared to control without material).
}
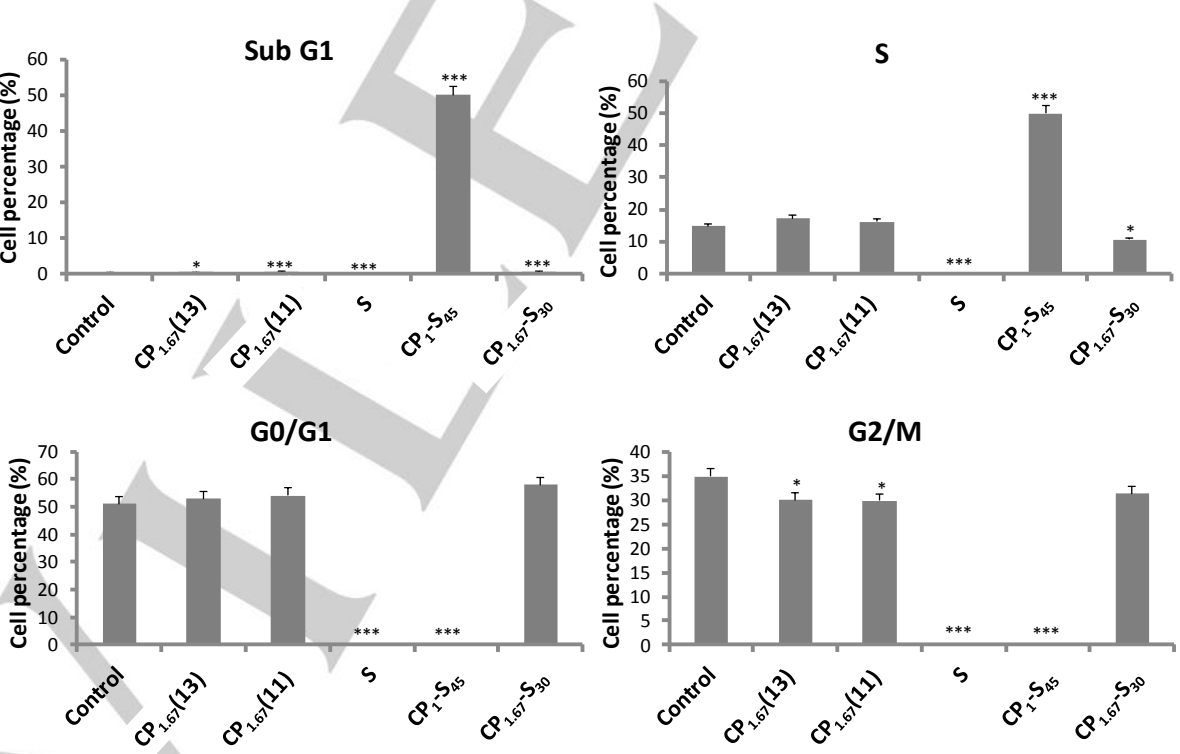

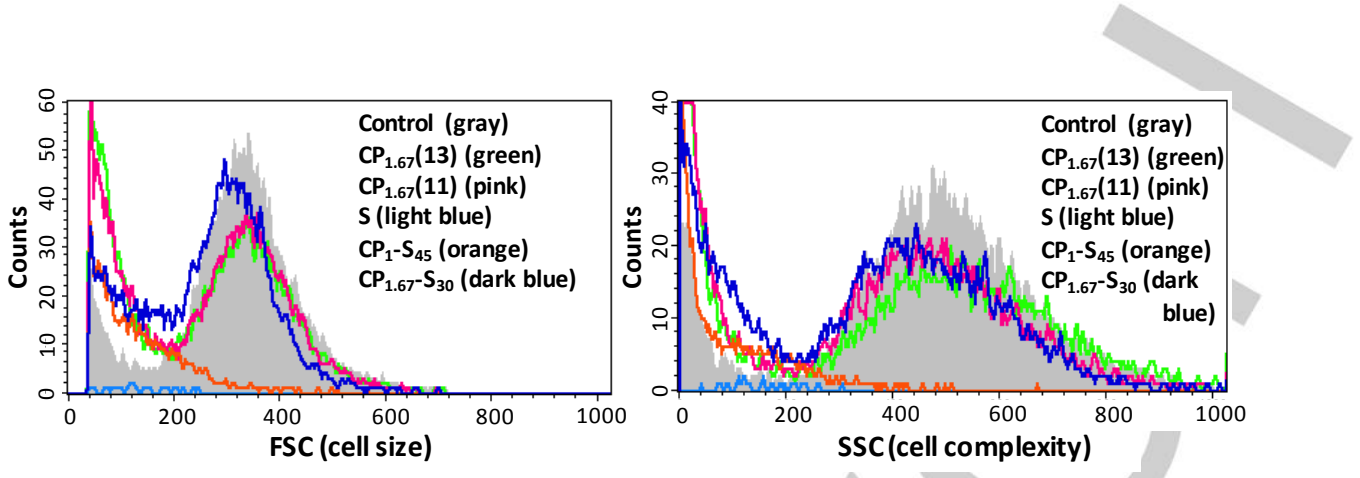

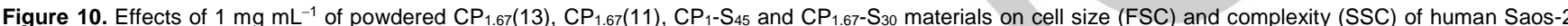
osteoblasts after 24 hours of treatment. Control = cells cultured without materials. $S=$ cells cultured with SDBS surfactant at the equivalent amount present in the hybrid materials.

The effects of all these materials on the cell size and complexity of human Saos-2 osteoblasts were also evaluated through FSC and $90^{\circ}$ SSC light scatters, respectively. These properties are determined by cell size, plasma membrane, cytoplasm, mitochondria, pinocytic vesicles, and lysosomes. ${ }^{[58]}$ Drastic effects of $\mathrm{CP}_{1}-\mathrm{S}_{45}$ and SDBS on these parameters were also observed (Figure 10), evidencing pronounced decreases of cell size and complexity.

Confocal microscopy was used to evaluate the human Saos-2 osteoblast morphology in the presence of all these materials after staining with rhodamine-phalloidin (for F-actin filaments in red) and DAPI (for nuclei in blue). The typical characteristics of this cell type were observed in the presence of $\mathrm{CP}_{1.67}(13)$ and $\mathrm{CP}_{1.67}(11) \mathrm{CaPs}$ and $\mathrm{CP}_{1.67}-\mathrm{S}_{30}$ hybrid material (Figure 11). However, $\mathrm{CP}_{1}-\mathrm{S}_{45}$ hybrid and SDBS surfactant induced important cell alterations and a decrease of cell size, in agreement with the FSC results obtained by flow cytometry (Figure 10).

$\zeta$-potential measurements of the in vitro studied samples were also carried out. The control materials possess the usual values for hydroxyapatite bare materials, ${ }^{[51]}-17.6 \mathrm{mV}$ for $\mathrm{CP}_{1.67}(13)$ sample, and the hybrid CaP based materials exhibited the values of -17.4 and $-25.2 \mathrm{mV}$ for $\mathrm{CP}_{1}-\mathrm{S}_{45}$ and $\mathrm{CP}_{1.67}-\mathrm{S}_{30}$ samples, respectively. Because the employed template is an anionic surfactant, these values are in accordance with a slight variance to more negative values. However, there are no significant differences to attribute the different in vitro behaviour of both hybrid samples to a change in the negative surface charge density. In addition, all previous characterization results of hybrid materials suggest that there is no significant difference in mineral composition and mesostructure to attribute the different behaviour observed in vitro between the two hybrid materials. Hence, both of them were maintained in culture medium under the same conditions as the in vitro assays, i.e., $37^{\circ} \mathrm{C}$ for $24 \mathrm{~h}$. Once recovered and washed, the sulphur content in the materials was analyzed, being very similar (Table 2). This would mean that both hybrid materials leach surfactant up to a stable value, equal for both, so that the material with higher content in SDBS releases more surfactant to the medium, explaining that the one with a lower content has a more stable mesostructure that becomes the hybrid material biocompatible.

Therefore, as expected, regardless of the CaP phase present in the control materials, apatite or a mixture of brushite and apatite, the SDSB-free materials are biocompatible. Pure SDBS surfactant is not biocompatible and, therefore, introduces toxicity in the hybrid $\mathrm{CaP}$ materials. However, below a certain amount of surfactant in the hybrids, the materials are biocompatible. A material with a low content in SDBS would be more biocompatible and besides it is crucial to carry out a previous stabilization of the hybrid material to minimize the loss of surfactant in the culture medium. The SDBS-free materials are biocompatible but do not present a mesolamellar structure. Indeed, the mesolamellar hybrid materials exhibit a lower biocompatibility but present improved properties regarding the possibility to host hydrophobic drugs, thus opening a promising research line as drug delivery systems. 

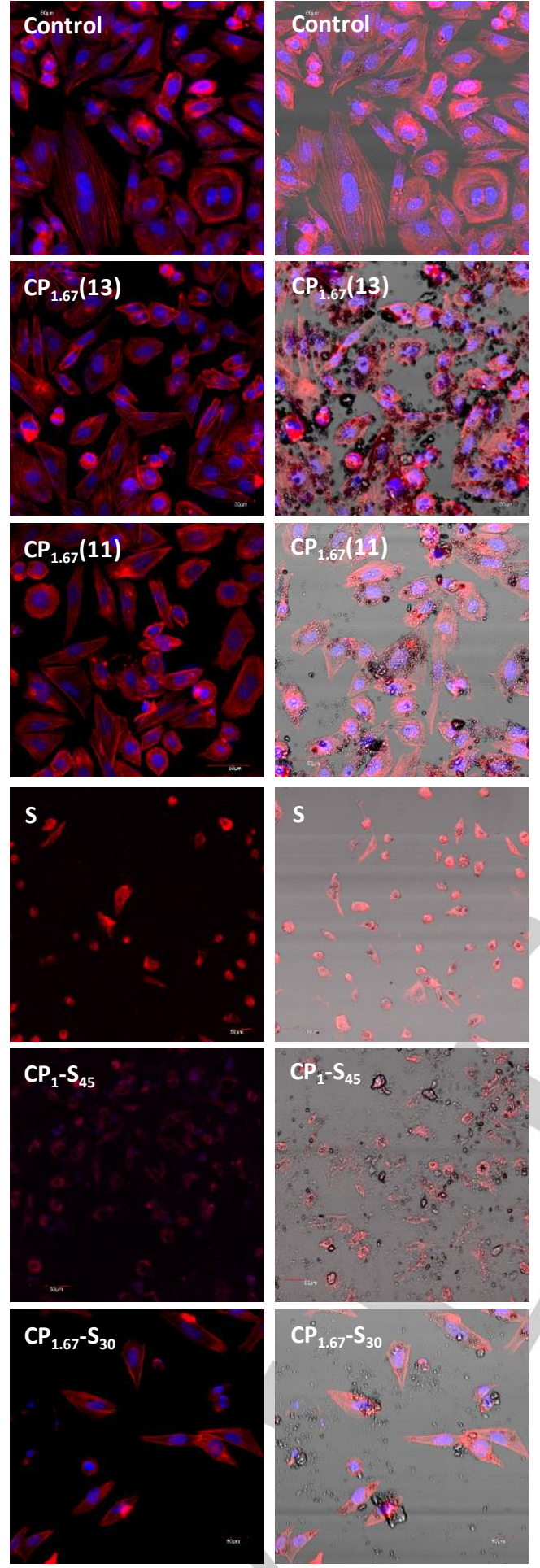

Figure 11. Effects of $1 \mathrm{mg} \mathrm{mL}^{-1}$ of powdered $\mathrm{CP}_{1.67}(13), \mathrm{CP}_{1.67}(11), \mathrm{CP}_{1}-\mathrm{S}_{45}$ and $\mathrm{CP}_{1.67-\mathrm{S}_{30}}$ materials on morphology of human Saos-2 osteoblasts observed by confocal microscopy after 24 hours of treatment. Actin was stained with rhodamine-phalloidin (red) and cell nuclei with DAPI (blue). Control $=$ cells cultured without materials. $S=$ cells cultured with SDBS surfactant at the equivalent amount present in the hybrid materials. The transmitted light images (right) show the absence or the presence of each material.

\section{Conclusions}

This research work demonstrates the ability of sodium dodecylbenzenesulfonate (SDBS) to obtain mesostructured calcium phosphates (CaPs). Hybrid materials based on $\mathrm{CaP}$ as mineral phase are obtained with a lamellar mesophase through the surfactant template self-assembly method and possibly a cooperative assembly of the $\mathrm{Ca}(\mathrm{SDBS})_{2}$ initially formed through ionic interactions between $\mathrm{Ca}^{2+}$ and sulfonate polar head of the SDBS surfactant. Regardless of the $\mathrm{Ca} / \mathrm{P}$ molar ratio used in the synthesis (1 or 1.67), the CaP phases identified are brushite, mixtures of brushite and apatite, and nanocrystalline apatite, in this sequence as the SDBS concentration in the synthesis increases. The lamellar mesostructure of the hybrid $\mathrm{CaP}$ materials was confirmed by the low angle XRD analysis and TEM. Nanoplates with a lamellar arrange presenting a curved structure is found. In addition, the repetition goes up to ca. 10 layers, therefore we have described this formation as a discontinuous lamellar mesophase.

Hence, novel hybrid materials consisting of mesostructured brushite and apatite phases have been synthetized and characterized. The experimental parameters have been optimized to obtain a novel hybrid materials consisting of CaPs mesostructured by the presence of SDBS. For hybrids containing only apatite as CaP phase, the minimum amount of SDBS incorporated was $39 \%$. However, when the inorganic phase was a mixture of apatite and brushite, hybrids containing $27 \%$ of of organic surfactant were obtained.

The in vitro study of two representative hybrids in contact with human osteoblast cell line shows that, upon the appropriate synthesis and stabilization conditions, a biocompatible hybrid can be prepared. Hence, it is possible to propose them for loading hydrophobic drugs in the organic interlayers, therefore acting as biomaterials in drug delivery systems.

\section{Supporting Information Summary}

Supporting Information is available from the Wiley Online Library or from the author. Experimental section (Reagents, Equipment, Synthesis of hybrid materials, Cell culture for the in vitro biocompatibility studies), FTIR spectra of hybrid materials (Figure SI.1), FTIR disscusion, TEM micrographs of $\mathrm{CP}_{1}-\mathrm{S}_{45}$ (Figure SI.2), TEM micrographs of $\mathrm{CP}_{1.67}-\mathrm{S}_{15}$ (Figure SI.3), XRD and FTIR of control materials $\mathrm{CP}_{1.67}(11)$ and $\mathrm{CP}_{1.67}(13)$ (Figure SI.4), TEM micrographs and ED pattern of control materials $\mathrm{CP}_{1.67}(11)$ and $\mathrm{CP}_{1.67}(13)$ (Figure SI.5), effects of $1 \mathrm{mg} \mathrm{mL}^{-1}$ of powdered $\mathrm{CP}_{1.67}(13), \quad \mathrm{CP}_{1.67}(11), \quad \mathrm{CP}_{1}-\mathrm{S}_{45}$ and $\mathrm{CP}_{1.67}-\mathrm{S}_{30}$ materials on cell cycle profile of human Saos-2 osteoblasts after 24 hours of treatment (Figure SI.6). 


\section{Acknowledgements}

This work was supported by European Research Council, ERC2015-AdG (VERDI), Proposal No. 694160; Ministerio de Economía y Competitividad (MINECO) grants MAT2013-43299R, MAT2015-64831-R and MAT2016-75611-R AEI/FEDER; Instituto de Salud Carlos III (ISCIII) grant PI15/00978, and FEDER funds of the European Union. CIBER is a public research consortium created by ISCIII which actions are cofunded by the European Regional Development Fund.

Keywords: biocompatibility $\cdot$ calcium phosphates $•$ lamellar mesostructures $\cdot$ organic-inorganic hybrid materials $\cdot$ surfactant templating

[1] M. Vallet-Regí, J.M. González-Calbet, Prog. Solid State Chem. 2004, 32, 1-31.

[2] S. V. Dorozhkin, Biomaterials 2010, 31, 1465-1485.

[3] S. Bose, S. Tarafder, Acta Biomater. 2012, 8, 1401-1421.

[4] S. Samavedi, A. R. Whittington, A. S. Goldstein, Acta Biomater. 2013, 9, 8037-8045.

[5] S. Pina, J. M. Oliveira, R. L. Reis, Adv. Mater. 2015, 27, 1143-1169.

[6] M. Vallet-Regí, D. Arcos, Nanoceramics in Clinical Use: From Materials to Applications. RSC Nanoscience \& Nanotechnology, 2016.

[7] M. Vallet-Regí, A. Rámila, R. P. del Real, J. Pérez-Pariente, Chem. Mater. 2001, 13, 308-311.

[8] A. L. Doadrio, A. J. Salinas, J. M. Sánchez-Montero, M. Vallet-Regí, Curr. Pharm. Design 2015, 21, 6189-6213.

[9] M. Vallet-Regí, Chem. Eur. J. 2006, 12, 5934-5943.

[10] M. Colilla, B. González, M. Vallet-Regí, Biomater. Sci. 2013, 1, 114-134.

[11] A. Baeza, M. Manzano, M. Colilla, M. Vallet-Regí, Biomater. Sci. 2016, 4, 803-813.

[12] T. Yanagisawa, T. Shimizu, K. Kuroda, C. Kato, Bull. Chem. Soc. Jpn. 1990, 63, 988-992

[13] J. S. Beck, J. C. Vartuli, W. J. Roth, M. E. Leonowicz, C. T. Kresge, K. D. Schmitt, C. T. W. Chu, D. H. Olson, E. W. Sheppard, S. B. McCullen, J. B. Higgins, J. L. Schlenker, J. Am. Chem. Soc. 1992, 114, 1083410843.

[14] Q. Huo, D. I. Margolese, G. D. Stucky, Chem. Mater. 1996, 8, 11471160.

[15] F. Schüth, Chem. Mater. 2001, 13, 3184-3195

[16] S. Mann. Biomineralization: Principles and Concepts in Bioinorganic Materials Chemistry. Oxford University Press, 2001.

[17] M. J. Olszta, X. Cheng, S. S. Jee, R. Kumar, Y.-Y. Kim, M. J. Kaufman, E. P. Douglas, L. B. Gower, Mater. Sci. Eng., R 2007, 58, 77-116.

[18] H. Cölfen, Nature Materials 2010, 9, 960-961.

[19] M. Antonietti, M. Breulmann, C. G. Göltner, H. Cölfen, K. K. W. Wong, D. Walsh, S. Mann, Chem. Eur. J. 1998, 4, 2493-2500.

[20] A. Kawska, O. Hochrein, J. Brickmann, R. Kniep, D. Zahn, Angew. Chem. Int. Ed. 2008, 47, 4982-4985.

[21] S. S. Jee, L. Culver, Y. Li, E. P. Douglas, L. B. Gower, J. Crystal Growth 2010, 312, 1249-1256.

[22] K. Bleek, A. Taubert, Acta Biomater. 2013, 9, 6283-6321.

[23] D. E. Rodriguez, T. Thula-Mata, E. J. Toro, Y.-W. Yeh, C. Holt, L. S. Holliday, L. B. Gower, Acta Biomater. 2014, 10, 494-507.

[24] M. H. Misbah, M. Espanol, L. Quintanilla, M. P. Ginebra, J. C. Rodríguez-Cabello, RSC Adv. 2016, 6, 31225-31234.
[25] A.-W. Xu, M. Antonietti, S.-H. Yu, H. Cölfen, Adv. Mater. 2008, 20 1333-1338.

[26] N. A. J. M. Sommerdijk, G. de With. Chem. Rev. 2008, 108, 4499-4550.

[27] J. Yao, W. Tjandra, Y. Z. Chen, K. C. Tam, J. Ma, B. Soh, J. Mater Chem. 2003, 13, 3053-3057.

[28] B. Prélot, T. Zemb, Mater. Sci. Eng., C 2005, 25, 553-559.

[29] Y. F. Zhao, J. Ma, Microporous Mesoporous Mater. 2005, 87, 110-117.

[30] H. Guo, F. Ye, H. Zhang, Mater. Lett. 2008, 62, 2125-2128.

[31] H. C. Shum, A. Bandyopadhyay, S. Bose, D. A. Weitz, Chem. Mater 2009, 21, 5548-5555.

[32] Z. Xia, L. Liao, S. Zhao, Mater. Res. Bull. 2009, 44, 1626-1629.

[33] N. Ikawa, H. Hori, T. Kimura, Y. Oumi, T. Sano, Microporous Mesoporous Mater. 2011, 141, 56-60.

[34] P. J. T. Reardon, J. Huang, J. Tang, J. Biomed. Mater. Res., A 2015 103A, 3781-3789.

[35] G.A. Ozin, N. Varaksa, N. Coombs, J.E. Davies, D.D. Perovic, M. Ziliox, J. Mater. Chem. 1997, 7, 1601-1607.

[36] I. Soten, G.A. Ozin, J. Mater. Chem. 1999, 9, 703-710.

[37] S. M. Schmidt, J. McDonald, E. T. Pineda, A. M. Verwilst, Y. Chen, R. Josephs, A. E. Ostafin, Microporous Mesoporous Mater. 2006, 94, 330338.

[38] S. Zhang, Y. Wang, K. Wei, X. Liu, J. Chen, X. Wang, Mater. Lett. 2007, 61, 1341-1345.

[39] H. Zhai, W. Jiang, J. Tao, S. Lin, X. Chu, X. Xu, R. Tang, Adv. Mater 2010, 22, 3729-3734.

[40] H. Zhai, X. Chu, L. Li, X. Xu, R. Tang, Nanoscale 2010, 2, 2456-2462.

[41] N. Ikawa, Y. Oumi, T. Kimura, T. Ikeda, T. Sano, J. Mater. Sci. 2008, 43, 4198-4207.

[42] N. Ikawa, H. Hori, T. Kimura, Y. Oumi, T. Sano, Langmuir 2008, 24, 13113-13120.

[43] J. Jiang, Y. Fan, L. Zhang, H. Yang, Y. Chen, D. Zhao, P. Zhang, J. Mater. Sci. 2011, 46, 3828-3834.

[44] C. Liu, X. Ji, G. Cheng, Appl. Surf. Sci. 2007, 253, 6840-6843.

[45] G. Zuo, Y. Wan, X. Meng, Q. Zhao, K. Ren, S. Jia, J. Wang, Mater. Chem. Phys. 2011, 126, 470-475.

[46] Y. Wan, C. Wu, G. Zuo, G. Xiong, J. Jin, R. Guo, Z. Wang, H. Luo, Mater. Chem. Phys. 2015, 156, 238-246.

[47] N. A. M. Barakat, K. A. Khalil, F. A. Sheikh, A. M. Omran, B. Gaihre, S. M. Khil, H. Y. Kim, Mat. Sci. Eng., C 2008, 28, 1381-1387.

[48] C. Piccirillo, M. F. Silva, R. C. Pullar, I. Braga da Cruz, R. Jorge, M. M. E. Pintado, P. M. L. Castro, Mat. Sci. Eng., C 2013, 33, 103-110.

[49] F. G. Bordwell, D. Algrim, J. Org. Chem. 1976, 41, 2507-2508.

[50] C. McCallum, A. D. Pethybridge, Electrochem. Acta 1975, 20, 815-818.

[51] J. C. Elliott, Structure and Chemistry of the Apatites and Other Calcium Orthophosphates in Studies in Inorganic Chemistry, Volume 18. Elsevier, 1994.

[52] S. M. Bulatovic, Handbook of Flotation Reagents: Chemistry, Theory and Practice. Elsevier, 2007, p.139.

[53] J. M. Peacock, E. Matijevic, J. Colloid Interface Sci. 1980, 77, 548-554.

[54] Q. Shen, H. Wei, Y. Zhao, D. J. Wang, L. Q. Zheng, D.F. Xu, Colloids Surf., A 2004, 251, 87-91.

[55] T. Wang, H. Cölfen, M. Antonietti, J. Am. Chem. Soc. 2005, 127, 3246 3247.

[56] T. Wang, M. Antonietti, H. Cölfen, Chem. Eur. J. 2006, 12, 5722-5730.

[57] P. J. M. Smeets, K. R. Cho, R. G. E. Kempen, N. A. J. M. Sommerdijk, J. J. De Yoreo, Nature Mater. 2015, 4, 394-399.

[58] J. M. Udall, R. A. Moscicki, F. I. Preffer, P. D. Ariniello, E. A. Carter, A K. Bhan, K. J. Bloch, Adv. Exp. Med. Biol. 1987, 216, 821-827. 


\section{Entry for the Table of Contents}

Eye-catching headline: Mesolamellar calcium phosphates

\section{FULL PAPER}

Mesostructured lamellar calcium phosphates have been prepared via surfactant templating with sodium dodecylbenzenesulfonate. Synthesis parameters were optimized leading to a novel hybrid material consisting of mesolamellar apatite. The hybrids biocompatibility has been evaluated in vitro with human osteoblasts showing that biocompatible hybrids can be prepared, therefore suggesting their possible application as matrixes in drug delivery systems.

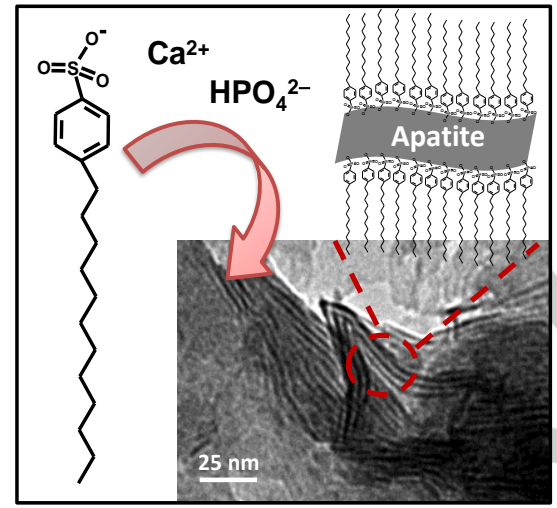

Antonio J. Salinas, José M. BlancoBécares, Okan Mersinlioglu, Laura Casarrubios, Daniel Fernández-Villa, María J. Feito, Teresa Portolés, Blanca González*, María Vallet-Regí

Page No. - Page No.

Synthesis, Characterization and Biocompatibility of Mesolamellar Calcium Phosphate Hybrids Prepared by Anionic Surfactant Templating 
Click here to access/download Supporting Information slct.201703130R2 Supp Info.pdf 